\title{
Short-term International Experience (STIE) and Students' Understanding of Quality Early Childhood Service Provision
}

\author{
Margaret Sims ${ }^{1} \&$ Yukiyo Nishida ${ }^{1}$ \\ ${ }^{1}$ University of New England, Australia \\ Correspondence: Margaret Sims, University of New England, Elm Avenue, Armidale, NSW 2351, Australia. \\ E-mail: margaret.sims@une.edu.au
}

Received: November 20, 2017

Accepted: December 10, 2017 Online Published: December 21, 2017

doi:10.5539/jel.v7n2p21

URL: http://doi.org/10.5539/jel.v7n2p21

\begin{abstract}
Exposing pre-service teachers to international professional experiences through a short-term visiting programme serves to challenge their understandings of good quality practice through disturbing assumptions and expectations previously formed through experiences in their own country/culture. Much of the research in international study focuses on pre-service teachers preparing to teach in primary, secondary or language classes. In this study we present the perceptions of pre-service early childhood students who underwent a short-term international experience. In particular we explore the ways in which their experiences impacted on their understandings of quality early childhood service provision. In the increasingly neoliberal Australian early childhood sector externally imposed standards define quality and this is enacted in relatively homogenous ways in practice, opportunities to observe practice arising from different understandings serves to challenge thinking, potentially leading to different world views (Piaget's accommodation).
\end{abstract}

Keywords: international professional experience, short term visiting programme, pre-service early childhood education, international study

\section{Introduction}

Incorporating international study in teacher education programmes is not a new idea. Research has demonstrated over many years that preservice teacher education students (henceforth called preservice teachers) who gain experience overseas are much better prepared to teach in multicultural classrooms and are more globally minded (Walters, Garii, \& Walters, 2009). Pre-service teachers who have had some kind of international experience are often found to be more culturally competent (Walters et al., 2009). Personally they are more likely to be self-confident, adaptable, resourceful and have a good self-esteem (Barkhuizen \& Feryok, 2006; Walters et al., 2009).

The duration of international experience impacts on the changes evident. Carlson \& Widaman (1988) showed that a year studying abroad had a major impact on US students' levels of international political concern, cross-cultural interest and cultural cosmopolitanism. It is assumed that the longer the time spent overseas the more lasting will be the impact. The impact of a significant period of study overseas (a year or more) can last a life-time (Dwyer, 2004). However shorter experiences have also been demonstrated to have impact. Anderson, Lawton, Rexeisen, \& Hubbard (2006) demonstrated improvements in cross-cultural sensitivity in US students who spent 6 weeks in Europe and the UK. These changes were demonstrated 4 weeks after the completion of the international study. Willard-Holt (2001) showed that a study tour of only 6 days demonstrated improvements in student empathy, tolerance, flexibility, patience and self-confidence a year afterwards. In contrast Houser (2008) and Nieto (2006) argue that even short cultural plunges (2 hour plunges), appropriately scaffolded and with support for reflection, can be very effective in helping students become more aware of their own values and biases and to improve their sensitivity.

Thus it is clear from the research that cross-cultural experiences can contribute to improving teachers' ability to work with diverse students. Increased understanding and sensitivity make it more likely teachers will modify curriculum and learning experiences to benefit each individual student and rely less on a standardised one-size-fits-all approach. However, in our current neoliberal world such an approach to diversity in the classroom, whilst encouraged in rhetoric, is not encouraged in reality (Connell, 2013; Davies \& Bansel, 2007; Giroux, 2013). Rather, a focus on standardised outcomes and standardised processes is prioritised so that 
centrally imposed curricula (national curricula for example) and pre-determined learning outcomes for each peer group of children are now the reality of many teachers' experiences internationally (Moss et al., 2016).

Whilst this is clearly evident in school education it is also becoming more prevalent in the early childhood sector and is clearly evident in Australia (Cheeseman, Press, \& Sumsion, 2015; Sims, Waniganayake, \& Hadley, 2017; Sumsion \& Grieshaber, 2012; Sumsion, Grieshaber, McArdle, \& Shield, 2014). In the Australian early childhood sector, these external controls (pre-defined definitions of quality, prescribed learning outcomes) position early childhood educators as technicians (Skattebol \& Arthur, 2014); practitioners whose role it is to follow pre-determined paths to deliver a pre-determined service. Given that they themselves have been educated in a neoliberal system where willingness to comply to external standards is highly rewarded and defines success (behaviours identified by Furedi, 2017; Giroux, 2015) it is not surprising that few are willing to challenge the hegemonic expectations imposed upon them, and instead, focus their energies on exploring how best to comply (Sims \& Waniganayake, 2015, 2016; Sims et al., 2017).

Thus preservice early childhood teacher education exists in considerable tension. Early childhood work is complex and requires considerable professional expertise in order to respond appropriately to events as they occur in day to day practice. Evans (2010) positions this as professionalism which requires a considerable level of autonomy coupled with trust from supervisors (managers and compliance regulators) that quality will not be undermined by well-trained professionals using their professional discretionary decision-making power. In reality, the complexity of every-day EC work makes the technical approach to practice difficult to perform leaving EC educators in a lose-lose situation: torn by the need for professional discretionary decision-making yet subject to technical expectations that define their daily practice. Resolving this tension requires high level thinking: the ability to make sense of the technical requirements, to have an in-depth understanding of quality and the professional confidence to modify their practices so quality may look different in different contexts depending on the children and families with whom they are working at any moment. Extant EC leaders in Australia are, in the main, struggling to find a balance in this context of tension (Sims et al., 2017). EC pre-service educators are expected, on graduation, to move relatively quickly into leadership positions (Sims et al., 2017) thus it is important that they are prepared, not just with the required technical skills, but with the ability to understand how quality can look different in different contexts, and the confidence to make discretionary decisions about the practices necessary to support each child and family in the best way possible.

Trying to develop this discretionary, professional decision-making skill is a challenge, particularly in a context where the curriculum and learning outcomes required in pre-service early childhood courses in Australia are tightly controlled by both state and federal agencies (established by legislation but operating independently of governments) and accreditation depends on meeting these external requirements. In the Australian context there are added complexities associated with different requirements at federal and state levels, and different requirements in the early childhood sector compared to the primary/secondary education sector into which early childhood is being more frequently positioned. Meeting all of these different requirements for accreditation provides no space in pre-service courses to provide any content that is not official, pre-approved and required.

Despite this, provision of cross-cultural learning experiences of some kind are clearly identified in the literature as a way students can be exposed to different understandings and different practices. It is therefore surprising that there is limited evidence in the literature that these experiences are routinely offered in early childhood pre-service programmes; rather the extant literature focuses on cross-cultural experiences in pre-service school teacher education and in vocational and higher education. Thus the purpose of this paper is to examine the emerging understandings of pre-service early childhood educators undergoing a cross-cultural experience. The university-based EC education degree (a 4 year full-time programme) in which we are involved offers students an opportunity to participate in a short-term international visit (as described in more detail below). The research reported in this paper explores the impact of this experience on their perceptions of quality with the aim of increasing our awareness of the ways in which disruptive experiences may impact on students' frameworks of understanding. This will help us in further developing the programme and planning how best to support student learning to ensure sustainability of impact. We wonder if such a short-term experience may contribute towards developing independent, professional discretionary decision-making skills to support different (or more nuanced) interpretations of quality than the hegemonic.

\section{Methodology}

\subsection{Conceptual Framework}

Piaget's theory proposes that a level of cognitive discomfort is necessary for significant changes in the way we think about the world (Piaget, 1952). Where we are surrounded by like-minded people, all of whom have similar 
experiences, we are likely to learn by adding new information to our extant understandings of the world (Piaget calls this learning by assimilation). However experiencing challenges which make us feel uncomfortable are the only way in which we can change our understandings of the world and grow cognitively (a process Piaget labels accommodation). This disequilibrium or cognitive struggle can be provided by experiences in cultures other than our own and it is this that Houser (2008) and other researchers including Marx \& Moss (2011) and Trilokekar \& Kukar (2011) use as the foundation of their cultural plunge/international teacher exchange/immersion programmes. These disruptive experiences, supported by professional and personal reflection, provide opportunities for significant cognitive and personal growth.

Trilokekar \& Kukar (2011) incorporate this into transformative learning theory which they claim provides a "framework for how lived experiences" provide a context for making meaning of the world (p. 1141). The theory suggests that disruptive and challenging experiences provide an opportunity for critical reflection that can lead to discarding old understandings and forming new ones (accommodation). Thus the disruptive experiences provide a catalyst for learning that can ultimately be beneficial if it is accompanied by critical reflection.

Trilokekar \& Kukar (2011)'s transformative learning theory parallels research in business and administration's organisational theory where the focus is on how practitioners interpret policy and enact it in their practice. Weick (2012)'s concept of sense making is relevant here as it explores the ways in which practitioners develop their understandings of the policies they are required to enact in their day to day work. Weick, Sutcliffe, \& Obstfeld (2005, p. 409) explain that "sense making occurs when a flow of organizational circumstances is turned into words and salient categories." In other words policy requirements are tested against educators' models of the world and places are found where they fit (equivalent to Piaget's assimilation). However "when the current state of the world is perceived to be different from the expected state of the world "(p409, as occurs with disruptive experiences in short-term international experience-STIE) students are prompted to create "plausible stories" (p. 410) to bring new meaning into existence. That new meaning then forms part of their ongoing sense making, continuing to influence their thinking on their return to their home country. In a similar manner to Piaget where information is categorised, sense making is also about labelling and categorising information so that it informs action.

In this study we are interested in exploring the students' understandings of quality EC service provision. They begin their Japanese tour with understandings based on their Australian experiences: for most these have arisen from placements in Australian EC services subject the Australian National Quality Standard (Australian Children's Education and Care Quality Authority, 2011) and working with the Australian EC curriculum, the Early Years Learning Framework (the EYLF-Department of Education Employment and Workplace Relations, 2009). In Japan they are exposed to different practices underpinned by different understandings of quality. These experiences disrupt their existing models of quality EC service provision. Reflection on these disruptions generates, we hope, changes in their thinking and understandings (reflecting both sense making, and, we hope accommodation) that may, in the future, enable them to move away from technical practice to a more critical approach to their EC work.

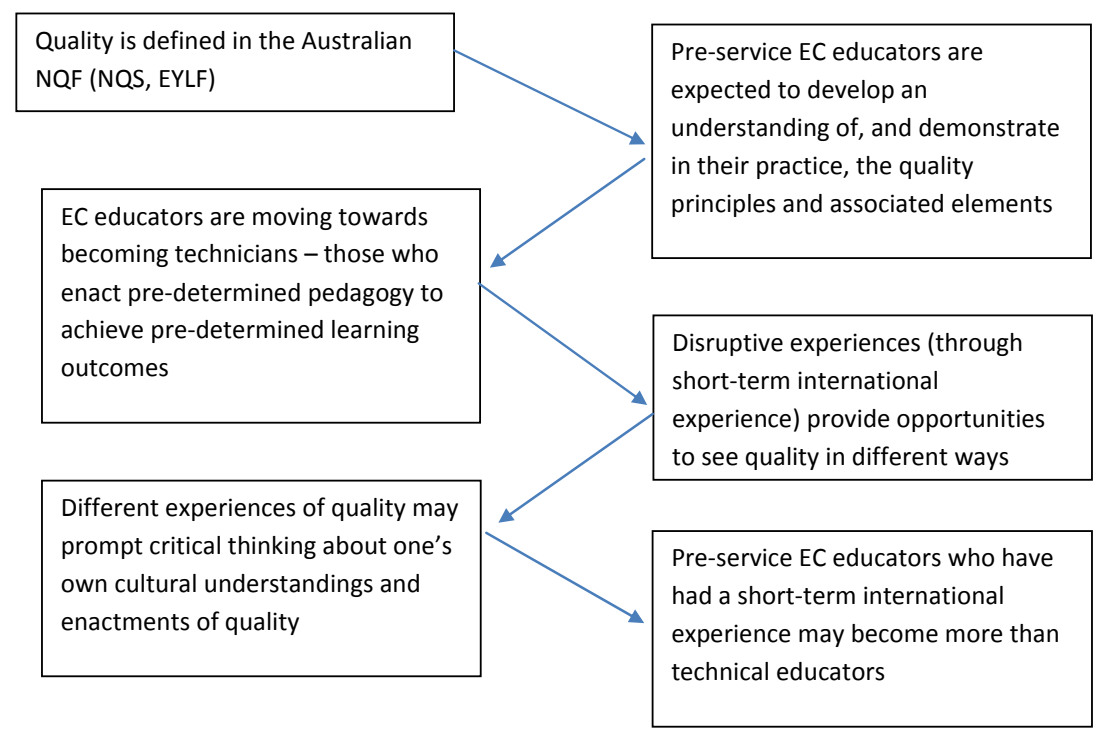

Figure 1. An overview of the assumptions underpinning the conceptual framework 


\subsection{The STIE Model and Link to the Research}

The Early Childhood Japan Study Programme took 12 students from the University of New England to Japan to participate in the early childhood Japan study tour programme for two weeks in November/December 2016. The students and their support staff visited eight early childhood programmes (Note 1) and worked with Japanese children through various art activities. The observation of different types of early childhood settings and teaching methods was an essential part of the learning process.

The experience was embedded in a visual art module/unit in their course and aimed to help the students to understand diversity in culture and arts within Japanese cultural heritage. Through guided exposure to some of traditional art forms in Japan, such as painting, and origami, traditional music, the programme aimed to deepen the students' understanding and appreciation of the long and rich history of the arts in Japan.

\subsection{Participants}

Twelve students participated in the STIE and 9 of these agreed to participate in the research. These students are identified by numbers 1-9 in order to protect their identity. These 9 students provided the data gathered in Stage 1 of the research. These 9 students:

- Were all female

- $\quad$ Aged between 20 to 23 years of age

- 4 had never travelled outside of Australia before

- 7 came from a rural background and the remainder were from regional or metropolitan cities

Three of these 9 students chose to participate in Stage 2 of the study. We do not provide any demographic information of these 3 students in order to protect their identity.

\subsection{Method and Procedure}

We used a photo-elicitation approach specifically to support participants' agency and power in the research given the power differentials between the students and the academic researchers. Rumpf (2017) and other researchers (for example Leonard \& McKnight, 2015; Miller, 2016; Richard \& Lahman, 2015; Stahl, 2017; Torre \& Murphy, 2015) identify participant-generated photo-elicitation as particularly effective in this regard, ensuring "participants have a voice in the research process and generates[ing] a surprising depth of information while responsibly approaching the sensitive nature of such research" (Rumpf, 2017, p. 21). In our approach we asked participants to photograph what was meaningful to them. Participants were then asked to select one photo from each preschool visit and reflect on what that photo conveyed to them. Reflections were then recorded in written words. This approach to recording reflections was chosen specifically because, as Weick et al. (2005) argue, reading and writing are crucial elements supporting sense making. In addition, pragmatically, providing written reflections each day was easier to manage in a busy visit schedule than would be other alternatives for recording reflections. We particularly wanted students to record their reflections daily so their experiences were fresh in their minds.

\subsubsection{Stage 1}

In stage 1, students took photos as described below and these formed the basis of their written reflections. In this manner we were able to obtain insight into their "thoughts, feelings, experiences and understandings" (Richard \& Lahman, 2015, p. 4).

The Stage 1 research procedure (as distinct from the necessary briefings about the STIE itself) involved:

1) An initial meeting with students to discuss the research, share the aims and brief students in relation to data collection.

2) Clear guidelines about the kinds of photos it would be ethically and culturally appropriate to take, including guidelines in relation to ethical and professional sharing of photos

3) Linking the research to the online teaching site (the home university uses Moodle) where students had access to resources, information, support from staff not taking part in the visit, and a secure place to upload their research data daily.

4) As part of the STIE students were asked to take as many photos as they liked (within the ethical guidelines)

5) At the end of each visit, for the research, students were required to select ONE photo that best represented the key thing they had learned from that visit

6) They then wrote a brief reflection about the chosen photo addressing the following questions: 
a. What does the photo say to you?

b. What did you learn?

c. Your thoughts or feelings about the photo

7) Students uploaded their photo and reflections onto the Moodle site daily - these were visible only to the approved teaching staff and the approved student members of the site

\subsubsection{Stage 2}

The following March ( 3 months after the STIE) all 9 students were asked to participate in a focus group. Three chose to do so. At this focus group we again used a photo-elicitation approach. Three months after the visit these photos were used to remind students of their experiences and, through interaction, "provide insights that might otherwise remain closed to the researcher" (Leonard \& McKnight, 2015, p. 630). In this sense the photos were used to "prompt comments, memory, reflection and discussion" (Miller, 2016, p. 264).

All the photos provided in Stage 1 were printed in hard copy and given to the students. They were asked to select ONE each that best represented what they had taken from the STIE experience as a whole. Each student was then asked to explain why that choice - what the photo meant to them and what they had learned. As part of the discussion others were able to contribute to each reflection. Thus the focus group provided an opportunity for collaborative discussion which, as Dean et al. (2017) suggests, supports deeper reflection.

\subsection{Analysis}

Students' written reflections and the focus group transcript were analysed using a process of constant comparison as originally proposed by Glaser (1965). This involved multiple readings of the written material initially coding for similarities and differences identified between the Australian services with which they were familiar and their Japanese EC experiences, and for any reflection of how their experiences might impact on their practice. At the completion of this level coding, each of the themes were perused to identify boundaries and subgroups within the themes. At the end of this process material was again perused for what the analysis had missed: ie ideas that were not encompassed by the extant coding and ideas that were only present once. Each of the themes was then matched, if possible, to material contained in the Australian National Quality Standard (Australian Children's Education and Care Quality Authority, 2011) which forms the basis of Australian understandings of EC quality.

In this paper, in the interests of clarity, two of the identified themes are discussed. These two themes are the ones that appeared in the student data the most and thus can be taken to represent the most impactful areas where students experienced disruption. A future paper will discuss the remaining themes.

\subsection{Ethical Issues}

The research was approved by the Human Ethics Committee of the home university. This committee follows the nationally mandated Australian guidelines for research (National Health \& Medical Research Council, Australian Research Council, \& Australian Vice-Chancellors' Committee, 2007 [updated 2015]). It was important to address the power differentials between students and staff in the research and to ensure that students felt free to participate in the STIE and NOT the research if that was their choice. Students were briefed about their rights and neither of the researchers was involved in marking their assessments for the unit of study in which they were enrolled in order to participate in the STIE.

In Stage 1 we identify students by number (Student 1 -Student 9) to protect their identity. We have specifically chosen not to number students in the focus group because there were only three and we did not want to risk identification. Thus in the focus group data we simply report using phrases such as "a student said" rather than identifying the student by number.

\section{Results and Discussion}

In this section the two key themes arising from the data are discussed. Comparisons are made with international literature and Australian understandings of quality. We not only demonstrate where students experienced disruption, we examine the evidence for impact of that disruption on their thinking and practice. The results are summarised in Table 1 below: 
Table 1. Summary of themes and elements of each theme

\begin{tabular}{|c|c|c|}
\hline $\begin{array}{l}\text { Main challenge to understandings of } \\
\text { quality }\end{array}$ & Elements & Students' photos and reflections \\
\hline Quality is about keeping children safe & $\begin{array}{l}\text { Risky play } \\
\text { Hazards vs risks } \\
\text { Safety } \\
\text { Risk aversion }\end{array}$ & $\begin{array}{l}\text { Height of equipment } \\
\text { Lack of soft fall under high equipment } \\
\text { Lack of straps on chairs } \\
\text { Supervision by educators } \\
\text { Role of peers } \\
\text { Self monitoring }\end{array}$ \\
\hline Sustainability I & $\begin{array}{l}\text { Use of natural material } \\
\text { outdoor play spaces }\end{array}$ & $\begin{array}{l}\text { Wood } \\
\text { lack of primary colours and plastic }\end{array}$ \\
\hline Organic & Connecting with nature & $\begin{array}{l}\text { Animals } \\
\text { Plants } \\
\text { Food }\end{array}$ \\
\hline Sustainability II & Responsibility for nature & Conservation of water \\
\hline Ecological views of pedagogy & Recycling & $\begin{array}{l}\text { Making toys and resources } \\
\text { Handmade }\end{array}$ \\
\hline $\begin{array}{l}\text { The simplicity of minimalist } \\
\text { pedagogic design }\end{array}$ & Minimising resources & $\begin{array}{l}\text { Fewer toys available } \\
\text { Spaces with no toys/resources } \\
\text { Imaginative play }\end{array}$ \\
\hline
\end{tabular}

\subsection{Quality is about Keeping Children Safe-Risky Play, Hazards and Safety}

The Australian National Quality Standard (Australian Children's Education and Care Quality Authority, 2011) includes a requirement that each child is protected (Standard 2.3). This is broken down into elements, the most relevant of which in this context are that this protection includes a requirement for children to be adequately supervised at all times (2.3.1) and that every reasonable precaution is taken to protect children from harm and any hazard likely to cause injury (2.3.2).

There is concern in the literature that we are becoming increasingly risk adverse and this attitude limits children's access to risky play (Sandseter \& Sando, 2016; Tremblay et al., 2015; van Rooijen \& Newstead, 2017; Warden, 2011). Sandseter and Kennair (2011) argue limiting children's access to risky play may have long-term negative impacts including an increase in neuroticism or psychopathology. This is evident in Australia where Wyver et al. (2010) argue safety concerns are linked with increasing child obesity, other health problems associated with inactivity and even increased exposure to vehicle pollution as children spend more time in cars being driven places.

It is in this context that the literature identifies the difference between risk and hazard, a distinction that is not always made by educators responsible for children's safety. Brussoni et al. (2015) use the term "risk" to identify a situation that challenges a child, and where the child is required to determine a relevant course of action. Risky situations can provide positive learning opportunities. In contrast, a hazard does not provide a learning benefit for children, and often is not something children can assess for themselves. It is clear that children can learn to assess risk for themselves and appropriate learning opportunities are needed to develop competence in this assessment (Lavrysen et al., 2015).

In the Australian context Wyver et al. (2010) argue that EC educators' understandings of, and attitudes towards safety/risk/hazard are key in determining their pedagogical approach to risky play. In particular they argue that adults position themselves as the best people to manage children's risk-taking, that adults see themselves as responsible for creating "good" (ie safe) play spaces and that the regulation of these play spaces is more important that the pedagogy that supports children's engagement in these spaces. Underpinning this are assumptions that restricting children's risky play is necessary and that all hazards must be eliminated. Pre-service EC educators are exposed to this attitude towards safety and risk, both in their classes and when they engage in professional placements.

The STIE experience prompted students to reflect on their understandings of risk and hazard. Reflecting on her first day and the photo she chose of a child's wooden chair, Student 1 wrote:

From all prac placements and casual working jobs I have only observed the use of high chairs and Velcro straps for this age group to keep children "secure" in their chairs at mealtimes." On day 6 this same student noted: "Sometimes in Australia we have many policies and practices in place that can stop ideas 
like this [making rope out of scrap fabric]. Such as children used to use toilet paper and paper towel rolls for craft activities and this is no longer due to hygiene reasons.

Over the course of their 8 visits nearly all the students reflected on the kinds of risks the children managed and the difference in the level of supervision offered by the EC educators. Student 2 took a photo of an outdoor area on day 4 and reflected: "This shows the children are provided with obstacles large enough to take some risks." On day 5 Student 3 chose a photo of swings in the outdoor play space and reflected: "this photo shows the different regulations in Japan compared to Australia. There isn't sufficient padding in case the children fall, which makes the risk of being hurt higher." The following day the same student noted: "the ladder and $\log /$ branches allows children to develop their grip and balance, although there is no protection if they fall ... I felt like this was too dangerous and the children would get seriously injured if they fell."

Students identified different levels of supervision in these risky situations than they had previously experienced in Australia. On day 7 Student 3 reflected: "Educators would be in the area however children of Japan are not necessarily "watched" and it allows for freedom and imagination to arise." In the focus group students reflected further on educator supervision. One stated: "we couldn't understand what they were saying but you wouldn't like see them standing there ... there were teachers floating around, like they were always watching..." another student added: "yeah watching but not like not right there." A third added: "No-one was ever in a child's face or at like a specific equipment. Like monitoring they got up the stairs fine and then went down the slide."

In the focus group one of the students chose a photo illustrating risk as the one most important element arising from her experiences. She said: "It's like play equipment and like it's so different to over here. Over there the stuff is really high ... like when you look—oh my god that's so dangerous ... we wouldn't be allowed to do stuff like that over here." Another student followed by stating: "It scared me" and the first student continued: "It was one of the main things I picked about this picture because, like the children are so aware of their own abilities and how far they can push themselves and that if they do push their bodies too far, they know what the risks are- - they are going to get hurt."

In the focus group students also used these photos to reflect further on the challenges offered to children. One student selected a photo of a classroom for toddlers as the one photo that best reflected her experiences and talked about the floor which was "bouncy - it was soft enough that you know you could feel like yourself bounce when you took a step. And these babies were all in this room with the educators and some of them were crawling around and others were like standing up with educators and like, just doing little bouncing movements". (It is interesting that in Stage 1 the bouncy floor was not identified in any of the photos or reflections.) Another student followed this train of thought and added: "one of the educators we talked to about how their grass was uneven and they'd done that purposefully so that they were aware of where they had to, like where their feet should go." This thought was finished by another student: "you couldn't run flat out-you sort of had to be careful." The first student positioned this as a deliberate pedagogical choice: "the ground isn't always going to be flat, so, you know have the ability to figure out."

\subsubsection{Impact}

The value of disrupting thinking is ultimately displayed in changes to practice. It is not clear from the students' reflections that the different conceptions of risk/hazard to which they were exposed will impact on their future practice. On day 8 Student 4 reflected: "I admire the Japanese have different regulations that allow high and "dangerous" structures to be an everyday part of their centre. Australia has very different regulations meaning we would struggle to be allowed to have such high structures but the children definitely enjoy taking risks and exploring in "dangerous" ways". A similar point was made by Student 3: "I was concerned about the risk involved in this activity as I am not used to seeing this in Australia." However, student 1 hinted there is potential for change: "I personally find in Australia learning spaces like this are still very achievable however it would be nice if we had less limitations with height restrictions and so forth as I am a firm believer that it's okay for children to be risk takers."

\subsection{Quality includes Teaching Sustainability}

The second key theme addressed in this paper is that of sustainable practices, an area identified in the Australian National Quality Standard (Australian Children's Education and Care Quality Authority, 2011), Principle 3.3. This principle requires services to take an active role in caring for its environment and to contribute to a sustainable future. In order to do so, services are required to embed sustainable practices (element 3.3.1) and support children to become environmentally responsible and to show respect for the environment (element 3.3.2) (Note 2). In addition to identification in the Australian National Standard, the Australian EC curriculum (the Early Years Learning Framework-EYLF) also addresses sustainability. The EYLF refers to the need to 
"highlight our responsibilities for a sustainable future and promote children's understanding about their responsibility to care for their environment (Department of Education Employment and Workplace Relations, 2009, p. 16).

In the Australian context meeting this has been difficult. The latest report from the accrediting body (Australian Children's Education and Care Quality Authority, 2017) shows that elements 3.3.1 and 3.3.2 are the $3^{\text {rd }}$ and $4^{\text {th }}$ most likely elements not to meet the required quality level, with Standard 3 overall the $3^{\text {rd }}$ most likely of all the standards to not be met (14\% of accredited EC services have not met this standard, $60 \%$ have met and $26 \%$ have exceeded the standard). Somerville \& Williams (2015) argue that the form of wording in the standard and curriculum position sustainability as something associated with the environment and not part of children's everyday social and community life. As a consequence understandings of sustainability tend to focus on children's connection to nature, and the idea of a nature-deficit disorder reflecting children's limited opportunities to be part of nature becomes part of this thinking. This element of sustainability is incorporated into students' reflections in two ways: (1) children in nature and (2) children responsible for looking after nature.

\subsubsection{Being in Nature through the Use of Natural Materials}

The use of natural materials was identified in the photos of a number of students. On Day 4 Student 2 reflected: "This photo shows part of play equipment in the centre which was made entirely out of wood/timber and other natural materials ... I believe more centres should focus their outdoor play spaces on natural play and natural materials. I feel natural materials are more calming and enjoyable for children to play with rather than synthetic and manmade materials." On day 7 Student 2 noted: "this photo shows an open planned room that allows for natural light to light the room. All doors, walls and windows are made from glass and are surrounded by timber used to build and furnish the room. This creates an open, calm and natural feeling space ... to me this picture shows how the beauty of the natural world around us is not always utilised to the extent it could be. Although it may seem distracting to have such a vast amount of glass and windows within a centre, it created a calming and open atmosphere where I believe children were able to more effectively use the space around them."

One centre was positioned adjacent to a forest area and maximised this placement through many windows. Student 3 reflected: "the children at this preschool were very fortunate to have access to a forest in their own backyard. It could be seen from the inside of the preschool as the centre was full of open glass windows along all walls and when children had access to outdoor play they had full control over where they wanted to go in the forest ... it became so evident that nature is simply a natural yet stimulating way for young children to learn."Student 4 also noted similarly: "the importance of natural based environments and how easy this can be achieved."

\subsubsection{Being in Nature through Engagement with Natural Things}

In addition to the use of natural materials some students identified nature elements available to children such as animals and plants that also reflect this idea of sustainability being about connecting with nature. Student 4 noted: "the Japanese seem to enjoy having animals in their centres such as rabbits, birds, chooks etc ... I appreciate the idea of having animal based experiences but also found it hard to believe they would keep animals in such small enclosures." Student 5 reflected: "the preschool want the children to be able to look, feel, smell the fruit and vegetables that the parents grow ... I feel this picture helps us understand that children need their own time to just observe and get a feel of the real world. If the children are never provided the opportunity to experience the real world at their own pace they may never have a true understanding of where they live and what they eat." At a different preschool Student 7 noted: "Even though the children live in the city they still earn about the procedure of growing and making rice." In the focus group students suggested that provision of these nature experiences was an important compensation addressing lack of opportunities in children's lives outside the preschool: "they don't actually get that at home ... we were talking about it and saying that the centres are probably so big because their houses are so small and it gives the children like a variety of options during the day."

\subsubsection{Being Responsible for Nature through Recycling/Re-Using}

A second understanding of sustainability presented by Sommerville and Williams (2015) is the idea of children's rights and responsibilities in relation to nature. Here is where the theme of recycling/re-using strongly evident in the data is located. Students particularly noted the hand-made toys and linked this to environmental consciousness. Student 4 wrote about her day 1 photo: "This particular centre put time and effort into hand making toys for the children, this was not for financial reasons. The Japanese believes it shows respect ... I learned how easy it is to create toys from recycled materials." Student 2 wrote: "The music table was made from different sized boxes, tape and elastic which was then decorated. The centre had many more toys made from 
boxes, bottle caps and other materials that can be easily recycled and accessed. This says to me that Australian childcare centres could focus on being more environmentally conscious and recycle and create more toys ... they can be made from basic, cheap recycled materials which can look and feel better than bought plastic toys." Student 3 also noted the same: "it shows that resources can easily be created, even with a small budget." Student 8 wrote about an outdoor game she had observed: "This was such a simple and effective outdoor game. The game does not require a lot of resources and would be easy to make. This game showed me that a lot of fun can be had from simple household materials." Student 9 wrote: "The children and teachers collected pinecones and have the chance to decorate them however they like to and stick it onto the tree (green cardboard. I like how children are able to use natural resources." Student 1 reflected: "Co-construction is a big theme here along with recycling old materials such as clothes to tie together in order to make the rope [the subject of her chosen photo]." Student 6 wrote about children using old tee-shirts to weave a skipping rope. She wrote: "I feel through this children learn to respect and appreciate their environment".

Student 6 linked what she saw back to her Australian experience: "I learnt that there are a number of ways to be more sustainable than we are in Australia. Preschools in Australia follow sustainable practices such as using different recycling bins, having water tanks and vegetable gardens. Before my visit to Japan I thought that was fantastic, however, upon visiting this preschool I have learnt that there are so many more ways in which we can be sustainable. This preschool had a use for almost every kind of "rubbish", everything would be turned into something new." Student 7 said something similar: "It shows me how their culture of recycling and not letting anything go to waste comes into practice. By using their imagination they have created something so simple that could have been expensive coming from a shop." Student 9 found it "amazing to see how much hand crafted materials they have." In the focus group one of the students selected a photo addressing recycling as the one photo that was most important to her from the whole experience. She said: "so many toys and this [the skipping rope in the photo] were made from recycled things by the educators."

\subsubsection{Being Responsible for Nature through Conserving Water}

In addition to recognising the different ways they observed EC educators recycling and re-using materials, students also noted in one preschool the way in which taps were provided as a learning experience. Student 7 noted: "Most children have only seen sensor taps which are automatic." Student 6 clarified: "the tap had proper handles rather than a sensor, which so many taps in Japan have. By having handles, this teaches the children that they have to turn the tap on for the water to come and then turn it off to stop the water." This leaning is reinforced by the fact that there were no basins provided under the taps. Student 8 reflected: "There was no sink located under the taps which allowed the water to run off onto the grass. This concept teaches children about water conservation and sustainability. The runoff from the water went on the grass rather than down a drain." Student 7 suggested: "it is a very smart way to let children immerse in water play while learning about the consumption of water and how to conserve as much as possible. The children can become aware of the consequences of leaving a tap on for even just a short time when a puddle begins to form on the ground." These experiences with the water taps suggested to Student 2 that: "more centres should have a place where children can access water for water play and watering the garden but also have a place for the water to be caught and saved. This allows children to independently engage in water play whilst being environmentally conscious." This thought was repeated later in the focus group: "these taps you have to actually turn on the water. Where does the water come from? It brings a whole new discussion to the take and like conserving water and why they do have sensor taps to conserve water ... whenever I've seen a tap in a centre here it's like: "Don't turn it on. Don't touch it."” Another student added: "The only taps the children play with in Australia are in the bathroom when they go to wash their hands." And a third student contributed: "When they're not meant to play but do anyway because that's the only option."

\subsubsection{Being Responsible for Nature through Minimising Resources}

The National Quality Standard (Australian Children's Education and Care Quality Authority, 2011) includes a requirement that there are sufficient resources, materials and equipment to enable effective implementation of the programme and to allow for multiple uses (Standard 3.2.2). In Australian EC settings this is often met through the creation of a range of different activity areas: for example the indoor area is often organised into a block corner, home corner, quiet reading space, a table with playdough, a painting area etc (for example see the professional development sessions on physical environment offered by Early Childhood Australia (Note 3) where each area provides an abundance of toys/resources for children's play.

On day 2 student 3 reflected: "It is clear learning can be almost seen as "organic", "natural" or a better term "original". There are no toys, materials or objects anywhere to be seen on this top level of the preschool... 
Children don't always need materialistic things to learn ... I feel that every place for children should create a space or implement a time and place where little or no materials are used so that children are encouraged to deepen their imaginations and creativity. It was amazing to see the games, continuous running, imaginative play and even CLIMBING [student capitalisation] of the trees." Student 1 also reflected on the same thing: "This centre does not provide toys or equipment on the rooftop. Children use their imagination to play and explore ... I have learned that children do not need to be constantly stimulated by equipment and toys and that creativity is an outcome when they are not provided with equipment." On day 5 at a different preschool, Student 5 reflected similarly: "This photo shows that the children are provided with an open space with little resources or materials. I learned that children do not need an environment filled with resources and materials to keep them occupied. I also noticed that they are capable in creating their own fun and games when provided with the right learning environment. This picture makes me feel happy. To see this environment work so well with the children is great. Australian children struggle to be entertained when they are provided with so many choices." Student 2 summed up this feeling when on day 7 she wrote: "I learnt that sometimes less can be more. This centre had minimal toys, no artworks covering the windows..."

\subsubsection{Impact}

It is not evident in the data that students developed a different understanding of sustainability from their experiences [particularly in relation to understanding sustainability in the different ways identified by Somerville and Williams (2015)] however what is evident to a small degree is that students may have taken ideas and incorporated them into their "toolbox" of professional ideas for practice. This appears to be a process similar to that of Piaget's assimilation rather than accommodation suggesting that rather than questioning understandings of quality (particularly in relation to the National Quality Standard Principle 3) students may use their experiences to simply find more ways to meet the standard. Student 4 day 1 wrote: "I loved the idea of recycling and making things for the children that in Australia we would just buy. I've learnt how easy it is to create things and how easy it would be to involve the children in making their own toys/play items." Student 6 listed a range of ways in which resources/toys could be created using recycled materials (eg "plastic bag pot plants, taped up and contact wrapped old juice and milk cartons to create building blocks"). Student 8 wrote: "This made me realise how much we waste recycled resources. Many of the centres I have visited on placements do not use recycled materials in their play and creative arts. I would love to see more of this in Australia."

\section{Conclusion}

We wanted to discover if our STIE would impact on students' frameworks for understanding quality EC service provision; if their sense making of the Australian policy which defines quality is modified by disruptive experiences presenting quality in different ways. The ultimate aim of the STIE is to support the development of EC graduate leaders who are capable of discretionary professional decision-making, influenced strongly, but not constrained, by policy. The data showed that in two main areas students were challenged by the different enactments of quality they observed.

In terms of risk/safety students were able to identify the important learning children gained by having access to greater levels of risk than those to which they had seen in Australia. They were able to identify children's skills in risk assessment and the different ways in which the EC educators provided supervision to create relevant learning opportunities for children. However, for most of the students it was not evident that this learning would be translated into their own practice. Several students claimed that Australian policies would constrain them from offering similar opportunities and only one student wondered about how she could offer a similar learning within the Australian framework. This suggests it is important that the STIE is followed up with further opportunities to explore how these kinds of learning opportunities might be enacted. Attitude change literature (for example as summarised in Bohner \& Dicke, 2010) suggests that for attitude change to result in practice changes, individuals need to receive information from multiple sources and they need to see how to implement new practices. It appears from this data that the STIE offered a different way to think about children's risk exposure/safety but that for changes to occur in student practice, they will need further support through other learning opportunities and practical experiences before we could be sure that their practice would reflect their learning. In terms of our conceptual framework, whilst it appears that the disruptive experiences have challenged students, they have not yet accommodated this learning.

A similar conclusion can be drawn in relation to students' experiences related to sustainability. Here, however, some of the students were able to see how some simple strategies could be enacted in Australia within the current policy framework. Simple games (tail tag for example) could be included in students' "professional tool box" (Piaget's assimilation). The focus on recycling/re-use it itself suggests a significant change in sense making 
(accommodation) in terms of the value placed on new/plastic versus re-used/natural and it does appear from their reflections that a number of students have shifted their understanding of what makes a resource a high quality resource through these experiences. It is important that in the remainder of their course back in Australia that they are exposed to other examples of re-use/recycling to cement this potential accommodation in their sense making.

Overall it appears that the disruptive experiences the STIE offered to students did offer opportunities to challenge their sense making and to begin the process of developing new frameworks that may support discretionary professional decision making in the future. However it is not evident that these changes are sustainable without ongoing support and exposure to new learning opportunities. The challenge remains, in our pre-service EC education programme, how do we continue to challenge students as they progress through their studies?

\section{References}

Anderson, P. H., Lawton, L., Rexeisen, R. J., \& Hubbard, A. C. (2006). Short-term study abroad and intercultural sensitivity: A pilot study. International Journal of Intercultural Relations, 30(4), 457-469. http://dx.doi.org/10.1016/j.ijintrel.2005.10.004

Australian Children's Education and Care Quality Authority. (2011). Guide to the National Quality Standard. Canberra, ACT: Australian Children's Education and Care Quality Authority.

Australian Children's Education and Care Quality Authority. (2017). NQF snapshot Q1 2017 (pp. 28). Sydney: Australian Children's Education and Care Quality Authority.

Barkhuizen, G., \& Feryok, A. (2006). Pre-service teachers' perceptions of a short-term international experience programme. Asia Pacific Journal of Teacher Education, 34(1), 115-134. https://doi.org/10.1080/13598660500479904

Bohner, G., \& Dicke, N. (2010). Attitudes and Attitude Change. Annual Review of Psychology, 62, 391-417. https://doi.org/10.1146/annurev.psych.121208.131609

Brussoni, M., Gibbons, R., Gray, C., Ishikawa, T., Sandseter, E. B. H., Bienenstock, A., ... Janssen, I. (2015). What is the relationship between risky outdoor play and health in children? A systematic review. International Journal of Environmental Research and Public Health, 12(6), 6423-6454. https://doi.org/10.3390/ijerph120606423

Carlson, J. S., \& Widaman, K. F. (1988). The effects of study abroad during college on attitudes toward other cultures. International Journal of Intercultural Relations, 12(1), 1-17. doi: http://dx.doi.org/10.1016/0147-1767(88)90003-X

Cheeseman, S., Press, F., \& Sumsion, S. (2015). An encounter with "sayings" of curriculum. Levinas and the formalisation of infants' learning. Educational Philosophy and Theory, 47(8), 822-832. https://doi.org/10.1080/00131857.2014.940825

Connell, R. (2013). The neoliberal cascade and education: An essay on the market agenda and its consequences. Critical Studies in Education, 54(2), 99-112. https://doi.org/10.1080/17508487.2013.776990

Davies, B., \& Bansel, P. (2007). Neoliberalism and education. International Journal of Qualitative Studies in Education, 20(3), 247-259. https://doi.org/10.1080/09518390701281751

Dean, J., Furness, P., Verrier, D., Lennon, H., Bennett, C., \& Spencer, S. (2017). Desert island data: an investigation into researcher positionality. Qualitative Research, O(0), 1468794117714612.

Department of Education Employment and Workplace Relations. (2009). Belonging, being and becoming. The Early Years Learning Framework for Australia. Canberra, ACT: Commonwealth of Australia.

Dwyer, M. (2004). More is better: the impact of study abroad program duration. Frontiers: The Interdisciplinary Journal of Study Abroad, 10, 151-163.

Evans, A. (2010). Professional discretion in welfare services: beyond street-level bureaucracy. Burlington, VT: Ashgate.

Furedi, F. (2017). What's happened to the university? A sociological exploration of its infantilisation. Abingdon, Oxon: Routledge.

Giroux, H. (2013). Neoliberalism's war against teachers in dark times. Cultural Studies $\leftrightarrow$ Critical Methodologies, 13(6), 458-468. https://doi.org/10.1177/1532708613503769 
Giroux, H. (2015). Dangerous thinking in the age of the new authoritarianism. Boulder, CO: Paradigm Publishers.

Glaser, B. (1965). The constant comparative method of qualitative data analysis. Social Problems, 12(4), 436-445. https://doi.org/10.2307/798843

Houser, N. O. (2008). Cultural plunge: a critical approach for multicultural development in teacher education. Race Ethnicity and Education, 11(4), 465-482. https://doi.org/10.1080/13613320802479034

Lavrysen, A., Bertrands, E., Leyssen, L., Smets, L., Vanderspikken, A., \& De Graef, P. (2015). Risky-play at school. Facilitating risk perception and competence in young children. European Early Childhood Education Research Journal, 1-17.

Leonard, M., \& McKnight, M. (2015). Look and tell: using photo-elicitation methods with teenagers. Children's Geographies, 13(6), 629-642. https://doi.org/10.1080/14733285.2014.887812

Marx, H., \& Moss, D. M. (2011). Please Mind the Culture Gap: Intercultural Development During a Teacher Education Study Abroad Program. Journal of Teacher Education, 62(1), 35-47. https://doi.org/10.1177/0022487110381998

Miller, K. (2016). Learning about children's school preparation through photographs: The use of photo elicitation interviews with low-income families. Journal of Early Childhood Research, 14(3), 261-279. https://doi.org/10.1177/1476718X14555703

Moss, P., Dahlberg, G., Grieshaber, S., Mantovani, S., May, H., Pence, A., ... Vandenbroeck, M. (2016). The Organisation for Economic Co-operation and Development's International Early Learning Study: Opening for debate and contestation. Contemporary Issues in Early Childhood, 17(3), 343-351. https://doi.org/10.1177/1463949116661126

National Health \& Medical Research Council, Australian Research Council, \& Australian Vice-Chancellors' Committee. (2007 [updated 2015]). National Statement on Ethical Conduct in Human Research. Canberra, ACT: Australian Government.

Nieto, J. (2006). The Cultural Plunge: Cultural Immersion as a Means of Promoting Self-Awareness and Cultural Sensitivity among Student Teachers. Teacher Education Quarterly, 33(1), 75-84.

Piaget, J. (1952). The origins of intelligence in children. New York: International Universities Press. https://doi.org/10.1037/11494-000

Richard, V. M., \& Lahman, M. K. E. (2015). Photo-elicitation: reflexivity on method, analysis, and graphic portraits. International Journal of Research \& Method in Education, 38(1), 3-22. https://doi.org/10.1080/1743727X.2013.843073

Rumpf, C. (2017). Decentering Power in Research with Criminalized Women: A Case for Photo-Elicitation Interviewing. Sociological Focus, 50(1), 18-35. https://doi.org/10.1080/00380237.2016.1218214

Sandseter, E. B. H., \& Kennair, L. (2011). Children's Risky Play from an Evolutionary Perspective: The Anti-Phobic Effects of Thrilling Experiences. Evolutionary Psychology, 9(2), 257-284. https://doi.org/10.1177/147470491100900212

Sandseter, E. B. H., \& Sando, O. J. (2016). "We don't allow children to climb trees" How a focus on safety affects Norwegian children's play in early-childhood education and care settings. American Journal of Play, $8(2), 178-200$.

Sims, M., \& Waniganayake, M. (2015). The performance of compliance in early childhood: Neoliberalism and nice ladies. Global Studies in Early Childhood, 5(3), 333-345. https://doi.org/10.1177/2043610615597154

Sims, M., \& Waniganayake, M. (2016). Performing early childhood leadership: struggles in a neoliberal context. An ethnotheatre performance. Paper presented at the The International Conference on Learning, Vancouver, Canada.

Sims, M., Waniganayake, M., \& Hadley, F. (2017). Educational leadership-an evolving role. Educational Management, Administration and Leadership, 20 pages downloaded. https://doi.org/10.1177/1741143217714254

Skattebol, J., \& Arthur, L. M. (2014). Collaborative practitioner research: opening a third space for local knowledge production. Asia Pacific Journal of Education, 34(3), 351-365. 
Somerville, M., \& Williams, C. (2015). Sustainability education in early childhood: An updated review of research in the field. Contemporary Issues in Early Childhood, 16(2), 102-117. https://doi.org/10.1177/1463949115585658

Stahl, G. (2017). The practice of "Othering” in reaffirming white working-class boys' conceptions of normative identities. Journal of Youth Studies, 20(3), 283-300. https://doi.org/10.1080/13676261.2016.1212163

Sumsion, J., \& Grieshaber, S. (2012). Pursuing Better Childhoods and Futures through Curriculum: utopian visions in the development of Australia's Early Years Learning Framework. Global Studies of Childhood, 2(3), 230-244. http://dx.doi.org/10.2304/gsch.2012.2.3.230

Sumsion, J., Grieshaber, S., McArdle, F., \& Shield, P. (2014). "State of play": Australian early childhood educators and play-based learning. Australasian Journal of Early Childhood, 39(3), 4-13.

Torre, D., \& Murphy, J. (2015). A different lens: using photo-elicitation interviews in education research. Education Policy Analysis Archives, 23(111), 26 pages downloaded. https://doi.org/10.14507/epaa.v23.2051

Tremblay, M. S., Gray, C., Babcock, S., Barnes, J., Bradstreet, C. C., Carr, D., ... Collyer, C. (2015). Position statement on active outdoor play. International Journal of Environmental Research and Public Health, 12(6), 6475-6505. https://doi.org/10.3390/ijerph120606475

Trilokekar, R. D., \& Kukar, P. (2011). Disorienting experiences during study abroad: Reflections of pre-service teacher candidates. Teaching and Teacher Education, 27(7), 1141-1150. http://dx.doi.org/10.1016/j.tate.2011.06.002

van Rooijen, M., \& Newstead, S. (2017). Influencing factors on professional attitudes towards risk-taking in children's play: a narrative review. Early Child Development and Care, 187(5-6), 946-957. https://doi.org/10.1080/03004430.2016.1204607

Walters, L., Garii, B., \& Walters, T. (2009). Learning globally, teaching locally: incorporating international exchange and intercultural learning into pre-service teacher training. Intercultural Education, 20(supp 1), S151-S158. https://doi.org/10.1080/14675980903371050

Warden, C. (2011). Wild things: risk in early childhood settings. Rattler(Autumn), 12-14.

Weick, K. E. (2012). Making Sense of the Organization, Volume 2: The Impermanent Organization (Vol. John Wiley \& Sons): Hoboken, NJ. https://doi.org/10.1002/9781119206453

Weick, K. E., Sutcliffe, K. M., \& Obstfeld, D. (2005). Organizing and the Process of Sense making. [Article]. Organization Science, 16(4), 409-421. https://doi.org/10.1287/orsc.1050.0133

Willard-Holt, C. (2001). The impact of a short-term international experience for preservice teachers. Teaching and Teacher Education, 17(4), 505-517. http://dx.doi.org/10.1016/S0742-051X(01)00009-9

Wyver, S., Tranter, P., Naughton, G., Little, H., Sandseter, E. B. H., \& Bundy, A. (2010). Ten Ways to Restrict Children's Freedom to Play: The Problem of Surplus Safety. Contemporary Issues in Early Childhood, 11(3), 263-277. https://doi.org/10.2304/ciec.2010.11.3.263

\section{Notes}

Note 1. We acknowledge that different countries/states use different terms including preschool, kindergartens, child care centres etc. The names of the services visited in Japan were all translated as preschools.

Note 2. Changes to the National Quality Standard to be implemented by October 2018 (see $\mathrm{http}: / / \mathrm{www}$.acecqa.gov.au/DecisionRIS) have reduced the number of principles related to sustainability to one

Note 3. http://www.ecrh.edu.au/resources/detail/index/case-studies-quality-area-3-physical-environment and http://www.earlychildhoodaustralia.org.au/nqsplp/wp-content/uploads/2012/05/EYLFPLP_E-Newsletter_No12. pdf

\section{Copyrights}

Copyright for this article is retained by the author(s), with first publication rights granted to the journal.

This is an open-access article distributed under the terms and conditions of the Creative Commons Attribution license (http://creativecommons.org/licenses/by/4.0/). 